\title{
A study of pattern of admission and outcome in a neonatal intensive care unit at Rural Haryana, India
}

\author{
Narayan $\mathbf{R}^{1}$, Singh $\mathbf{S}^{2}$ \\ ${ }^{1}$ Dr. Raghvendra Narayan, Associate Professor, Department of Pediatrics, Maharishi Markandeshwar Institute of \\ Medical Sciences and Research, Mullana, Ambala, Haryana, India, ${ }^{2}$ Dr. Shivani Singh, Senior Lecturer, \\ Department of Oral Pathology, Maharishi Markandeshwar College of Dental Sciences and Research, Mullana, \\ Ambala, Haryana, India.
}

Address for Correspondence: Dr.Raghvendra Narayan, Associate Professor, Department of Pediatrics, Maharishi Markandeshwar Institute of Medical Sciences and Research, Mullana, Ambala, Haryana, India. Address- B-5, B1 block, M.M. University Campus, Mullana, Ambala, Haryana, India. E-mail: drrgh1971@gmail.com,drrghvendra@rediffmail.com

\begin{abstract}
Background: Neonatal mortality rate contributes significantly tounder five mortality rates. Data obtained from pattern of admission and outcome may uncover various aspects and may contribute andhelp in managing resources, infrastructure, skilled hands for better outcome in future. Method: This was a retrospective study done in NICU at MM Institute of Medical Sciences. and Research, Ambala, India. Data of all admitted neonates were analyzed with regard toageof babies, sex, weight, cause of admissions and their outcome. Results: During study period a total of 175 neonates were analyzed. Male were predominant over female with maleto female ratio 1.21:1. Majority of newborns were to belonged to low birth weight $(46.28 \%)$ followed bynormal birth weight (30.28\%), very low birth weight (18.28\%) and ELBW babies. Maximum number of babies were premature (54\%) followed by neonatal sepsis (12.57\%), meconium aspiration syndrome (9.17\%) and birth asphyxia (9.14\%). Out of 175 babies $29(17.14 \%)$ were died. Highest mortality were found with prematurity (62\%) followed bybirth asphyxia (20.69\%) and neonatal sepsis (10.34\%). Conclusion: Prematurity, neonatal sepsis, birth asphyxia and meconium aspiration syndrome were the major indications of admissions. Prematurity, birth asphyxia and neonatal sepsis were major causes of mortality in my study. These mortalities can be reduced with improved management of antenatal and perinatal period, early recognition of conditions, timely intervention and early referral to higher centre.
\end{abstract}

Key words: Prematurity, Birth Asphyxia, Neonatal Sepsis, Low Birth Weight

\section{Introduction}

According to World Health Organization (WHO) 4 million newborn deaths occur worldwide every year [1]. Among these approximately $98 \%$ deaths occur in developing countries and are caused by infections, asphyxia, complications of prematurity and low birth weights [2].

Neonatal mortality accounts for nearly two-thirds of infant mortality rate and one-third of under-five mortalities world wide [3-5]. Neonatal period of a child is most vulnerable period. Infant mortality rate

Manuscript received: $28^{\text {th }}$ September 2017

Reviewed: $8^{\text {th }}$ October 2017

Author Corrected: $17^{\text {th }}$ October 2017

Accepted for Publication: $24^{\text {th }}$ October 2017 of anycountry reflects its socioeconomic status as well as health care efficiency, effectivenessand its outcome [6]. Neonatal immunity status is in maturity phase, so they are more pronetoinfections. Admissions in an Intensive Care Unit depend upon many factors like socioeconomic status, their cultural behavior, literacy, traditional believes and gender bias [7].

Gradually care of neonates are improving globally specially in developing countries and more trained hands and resources are continuously growing. Prematurity, infections and birth asphyxia are the most common causes of neonatal mortality. Many 
causes of neonatal morbidity and mortality are preventable. Besides vulnerability of newborn, morbidity and mortality also depends upon the level of care [8].

A knowledge of pattern of admissions and their outcomes in an NICU helps in making future planning, proper management and utilization of skilled hands and resources available.

The aim of this study was to assess the major causes leading to admissions in our NICU and their causes of death in relation to their conditions, to address past uncovered aspectsand gaps so that these willhelp to identify the more appropriate inter ventions that canbe instituted for a better outcome.

\section{Material and Methods}

This study was a retrospective observational study done at Maharishi Markandeshwar Institute of
Medical Sciences and Research, Mullana, Ambala, India. All the babies admitted between March 2016 to December 2016 in NICU were analyzed with respect to their age in days, sex, birth weight, cause of admission, hospital stay and their outcome. Babies having incomplete data andthose babies kept for observation only for less than 24 hours were excluded from the study. The catchment area of our NICU are local villages and villages specially from Saharanpur district of Uttar Pradesh, India. Facilities in our NICU are as 12 beds having 10 multipara monitors, 2 neonatal ventilator, 12 radiant warmers, 8 phototherapy (LED type) units and 6 syringe pumps.

All the diagnoses were made by their standard definitions. Chi-Square tests were applied to see the statistical differences between categorical variables. A p value less than 0.05 were taken as statistically significant.

\section{Results}

During the study period, total 175 neonates were admitted to NICU. Table 1 . shows out of 175 babies 107 were males and 88 were females with male to female ratio 1.21:1. The difference was found statically significant.

Table-1: Gender Based Admission Pattern.

\begin{tabular}{|c|c|c|c|}
\hline Gender & No. of admissions & Percentage & p value \\
\hline Males & 107 & 61.14 & 0.0381 \\
\cline { 1 - 3 } Females & 88 & 38.86 & \\
\hline Total & $\mathbf{1 7 5}$ & $\mathbf{1 0 0}$ & \\
\hline
\end{tabular}

Table-2: Birth Weight Based Admission Pattern.

\begin{tabular}{|c|c|c|c|}
\hline Birth weight & Admissions & Percentage & p value \\
\hline$>2.5 \mathrm{~kg}$ & 53 & 30.28 & \multirow{2}{*}{400001} \\
\hline LBW & 81 & 46.28 \\
\hline VLBW & 32 & 18.28 & \\
\hline ELBW & 9 & 5.14 & \\
\hline Total & 175 & 100 & \\
\hline
\end{tabular}

Table 2 shows the distribution of babies admitted according to their birth weights. ELWL were 9 (5.14\%), VLWL were $32(18.28 \%)$ and LBW were $81(46.28 \%)$ and remaining were normal birth weight neonates. The difference was found statistically significant.

Table 3 shows distribution of conditions causing NICU admissions. Maximum number of babies were preterm 96 (54\%), more than half of all the babies, followed by sepsis $22(12.57 \%)$, birth asphyxia $16(9.4 \%)$, neonatal jaundice 12 (6.85\%), Meconium aspiration syndrome. $10(5.71 \%)$ and the difference was statistically significant. 
Table-3: Cause based admission pattern.

\begin{tabular}{|c|c|c|c|}
\hline Cause & Admission & Percentage & \multirow{2}{*}{$<0.00001$} \\
\hline Preterm & 96 & 54.85 \\
\hline Neonatal Sepsis & 22 & 12.57 \\
\hline MAS & 17 & 9.71 \\
\hline Birth Asphyxia & 16 & 9.14 \\
\hline Neonatal jaundice & 12 & 6.85 \\
\hline Post term & 3 & 1.71 \\
\hline Surgical & 4 & 2.28 \\
\hline MAS & 17 & 9.71 \\
\hline Hypoglycemia & 1 & 0.05 \\
\hline Others (CHD, congenital malformation, & 4 & 2.28 \\
\hline
\end{tabular}

Table- 4: Pattern of admission and death based upon the birth weight.

\begin{tabular}{|c|c|c|c|}
\hline Birth weight & Death & Percentage & \multirow{2}{*}{0.6258} \\
\hline$>2.5 \mathrm{~kg}$ & 7 & 24.13 & \\
\hline LBW & 7 & 24.13 \\
\hline VLBW & 10 & 34.48 \\
\hline ELBW & 5 & 17.24 \\
\hline Total & $\mathbf{2 9}$ & $\mathbf{1 0 0}$ & \\
\hline
\end{tabular}

Table 4 shows the distribution of mortality in relation with their birth weight. Out of 29 deaths maximum belonged to VLBW group accounting 34.48\%, followed by LBW7 (24.13\%) and babies having normal birth weight (24.13\%) and ELBW (17.24\%) and the difference was found non-significant.

Table- 5: distribution of diseases causing death.

\begin{tabular}{|c|c|c|c|}
\hline Cause of death & No. of deaths & Percentage & \multirow{2}{*}{5.334} \\
\hline Preterm & 18 & 62.00 \\
\hline Birth Asphyxia & 6 & 20.69 \\
\hline Neonatal sepsis & 3 & 10.34 \\
\hline MAS & 2 & 6.89 \\
\hline Total & $\mathbf{2 9}$ & $\mathbf{1 0 0}$ & \\
\hline
\end{tabular}

Table 5 shows distribution of causes of death. Out of 175 admitted babies 29 were died with a mortality rate of $17.14 \%$. Maximum number of death were observed with preterm, 18 out of 29 with $62 \%$, their various complications followed by birth asphyxia (20.69\%). Third commonest cause of mortality was sepsis (10.34\%) which is followed by MAS (6.89\%) and was found statistically non- significant.

\section{Discussion}

The benefits of neonatal intensive care are clear and there has been a significantfall in neonatal mortality ratein developed countries with the advent of mechanical ventilation and the concept of neonatal intensive care [7,9]. In our study, a total of 175 babies were analyzed retrospectively. Male neonates predominate over female neonateswith a male to female ratio of 1.21:1. The male predominance inour study is consistent with other studies $[6,10]$ This predominance of male babies indicates that male neonates are more vulnerable during the neonatal period, a finding in agreement with the well described biological survival of girls [11].

With regard to birth weights of neonates admitted, maximum number of neonates belonged to LBW 
(46.28\%) followed by normal birth weight and VLBW (18.28\%). Similar findings were observed in studies done by Bhagat et aland Prasad V et al $[12,7]$.

More than half (62\%) of neonates were preterm and were found as most common indications of admission in NICU. Similar observations were found in studies done by Bhagat et al, Elizabeth $\mathrm{U}$ et al, and Prakash J et al $[9,12,13]$. Many studies reported lesser number of preterm admission in comparison to ourstudy $[14,6,7]$.

Second most common indications of NICU admission in our study were neonatal sepsis. Similar observation was found by Syed R. Ali [15]. Many researchers reported birth asphyxia as second most common cause of NICU admission [12]. Other important causes of indication of admission in NICU were birth asphyxia (20.69\%), meconium aspiration syndrome $(9.71 \%)$ and neonatal jaundice (6.85\%). Narayan R reported neonatal jaundice as most common cause of admission as most of the babies in their NICU came from high altitude [6].

Out of 175 neonates 29 (17.14\%) died in our study. Similar observations were found in studies of Bose O Toma etal, Ike Elizabeth U et aland Walanaet al. $[16,9,17]$. NarayanR found $8 \%$ mortalty in their study. Mortality rate of any neonatal intensive care unit depends upon many factors other thanthe clinical condition of the baby such as the infrastructure, man power, skilled hands etc. Hence the mortalityratereports vary widely in different studies from different regions. Mortality rate in relation tobirthweight were observed as in Normal weight (24.13\%), VLBW (34.48\%), LBW (24.13\%) and ELBW (17.24\%).

Most common condition causing highest mortality were preterm associated with their different complications. Second most common cause of mortality wasbirth asphyxia and third commonest was neonatal sepsis followed by meconium aspiration syndrome. Similar obser-vations were found by Bhagat et al[9].

Low birth weight is one of the leading cause of admission and mortality in most of the developing countries [18]. Immaturity tends to increase the severity and complications of most of the neonatal diseases.
Immature organs, therapeutic complications and specific conditions and complications in premature babies contribute to high rate of morbidity and mortality. Morbidity and mortality inversely related to their gestational age.

Therefore, prevention of morbidity and mortality related to prematurity will significantly reduce overall morbidity and mortality. Appropriate antenatal care, good obstetric practices, proper referral, improvement of facilities for caring for preterm babies as well as proper newborn care practices have been found to reduce morbidity and mortality from prematurity[ 19]. Neonatal sepsis is a significant cause of neonatal morbidity and mortality particularly in preterm, LBW babies [20, 21]. In our study it was the third most common cause of morality.

The incidence of neonatal sepsis in the developed countriesis $1-10 / 1000$ where as it is roughly three times in developing countries [22].

It is estimated that around $23 \%$ of all newborn deaths are caused by birth asphyxia [23]. Following improvement in antenatal and obstetrical care in most of the developed countries the incidence of birth asphyxia has reduced significantly and less than 1 per 1000 live births die from this. Syed R Ali et al and Saleem $\mathrm{M}$ etal found birth asphyxia asmost common cause of mortality in their studies $[15,10]$.

\section{Conclusion}

Prematurity, low birth weight, birth asphyxia, neonatal sepsis, meconium aspiration syndrome, neonatal jaundice were the leading causes of admission in NICU. Prematurity, birth asphyxia neonatal sepsis were the most common causes of mortality. These mortalities can be reduced with better management of antenatal care, improved perinatal care, promoting institutional delivery, early recognition and timely intervention with early referral to tertiary care centre.

Limitations of Study: Surgical cases after initial stabilization transferred to pediatric surgeryward were not followed.

Contributions: NarayanR contributed in making concept, design and acquisition of data and Singh S analyzed the data, drafted the article and revised critically. 
Funding: Nil, Conflict of interest: None initiated, Perission from IRB: Yes

\section{References}

1. World Health Organization. Perinatal mortality. A listing of available information.Geneva,WHO 1996:

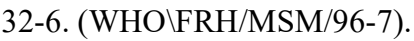

2. Black RE, Morris SS, Bryce J.Where and why are 10 million children dying every year? Lancet. 2003 Jun 28;361(9376):2226-34.

3. World Health Organization. Mother-baby package: implementing safe motherhood in countries. Maternal Health and Safe Motherhood Programme. Geneva, WHO 1994. (WHO /FHE/ MSM/94.11).

4. Saving Newborn Lives. State of World's Newborns. Save the Children Federation2001;1-49.

5. World Health Organization. Management of Sick Newborn.Report of a Technical Working Group, Ankara.

6. Narayan R . A study of the pattern of admissions and outcome in a neonatal intensive care unit at high altitude. Sri Lank J Child Health 2012;41 (2): 79-81.

7. Veena Prasad and Nutan Singh. Causes of morbidity and mortality admitted in Government Medical College Haldwani in Kumoun Region Uttarakhand India. JPBMS (Journal of Pharmaceuticals and Biomedical Sciences) 2011;9 (23):1-4.

8. Bang AT, Bang RA. Diagnosis of causes of childhood deaths in developing countries by verbal autopsy : suggested criteria. The SEARCH Team. Bull World Health Organ 1992;70((4):499-507.

9. Ike Elizabeth U, Modupe O, Oyetunde. Pattern of Diseases and Care Outcomes of Neonates Admitted in Special Care Baby Unit of University College Hospital, Ibadan, Nigeria from 2007 To 2011, IOSR J Nursing Health Science 2015;4(3): 62-71.

10. Saleem M, Raghib I, Shahjad B, Mubarak Ali, Zahid K. Pattern of neonatal admissions and its outcome in a tertiary care hospital of Southern Punjab (a 5 years study). PJMHS 2014;8(4):916-21.
11. Roy RN, Nandy S, Srivastava P, Chakraborty A, Dasgupta M, Kundu TK. Mortality Pattern of Hospitalized Children in a Tertiary Care Hospital of Kolkata. Ind J Community Med 2008; 33 (3): 187-89.

12. Baghel B, Sahu A, Vishwanadham K. Pattern and Admission and Outcome of Neonates in NICU of Tribal Region Bastar, India.Int J Med Res Prof 2016; 2(6):147-50.

13. Parkash J, Das N. Pattern of admissions to neonatal unit. J Coll Physicians Surg Pak. 2005 Jun;15(6):341-4.

14. MS Hoque, S Alam et al. Pattern of Neonatal Admissions and Outcome in an Intensive care Unit of a Tertiary Care Paediatric Hospital in Bangladesh- A One- year Analysis. Journal of Bangladesh College of Physicians and Surgeons 2013; 31 (3): 134-39.

15. Syed R. Ali, Shakeel Ahmed et al. Disease Patterns and Outcomes of Neonatal Admissions at a Secondary Care Hospital in Pakistan Sultan Qaboos Univ Med J 2013; 13 (3): 424428.

16. Bose O.Toma, Olukemi O Ige, Ibrahim I Abok, Carol O, Rose O,Amina D. Pattern of neonatal admissions and outcome in a tertiary institution in north central Nigeria. J. of Medicine in the Tropics 2013;15(2):121-25.

17. Walana W, Acquash EKS, Abdul MA, NaafuB, Aruk E, Vicar KE et al. Pattern, causes and treatment outcomes of neonatal admission in the Tamale Teaching Hospital. Clinics Mother Child Health 2016; 13 (4). DOI: 10. 4172/2090- 7214. 1000252.

18. Ahmed ASMNU, Rob MA, Rahman F, Rahman R, Huda N. Preterm Very Low Birth Weight Babies: Outcome of Admitted Newborns at a CommunityLevel Medical College Hospital in Bangladesh. J of Bangladesh College of Physicians and Surgeons 2008; 26 (3): 128-34.

19. Olowonyo T, Oshin S, Obansanjo-Bello I. Some factors associated with low birth weight in Ogun State, Nigeria. Niger Med Pract 2006; 49 (6): 154-7. 
20. Stoll BJ, Hansen N.Infections in VLBWinfants: studies from the NICHD NeonatalResearchNetwork. SeminPerinatol. 2003 Aug; 27(4):293-301.

21. Stoll BJ, Hansen NI Adams-Chapmani, Fanaroff AA, Hintz HR, VohrB, Higgins RD. Neuro developmental and growth Impairment among Extremely Low-Birth-Weight infants with Neonatal infections. JAMA2004; 292: 2357-65. doi:10.1001 ljama. 292.19.2357.
22. Ahmed ASMNU, Chowdhury MAKA, Hoque MM,Darmstadt GL. Clinical and Bacteriological Profile of Neonatal Septicemia in a Tertiary level Pediatric Hospital in Bangladesh. Indian Pediatrics 2002; 39 (11):1034-9.

23. Lawn J, Shibuya K, Stein C. No cry at birth: globalestimates of intrapartum still births and intrapartum- related neonatal deaths. Bull World Health Organ. 2005; 83(6):409-17.

\section{How to cite this article?}

Narayan R, Singh S. A study of pattern of admission and outcome in a neonatal intensive care unit at Rural Haryana, India. Int J Pediatr Res. 2017;4(10):611-616.doi:10. 17511/ijpr.2017.i10.05. 